\title{
Teaching Surgical Skills During the Present Explosion of Knowledge and Technologies
}

\author{
Mohamed Osman Mohamed Suliman* \\ Department of Surgery, Nile College, Khartoum \\ *Corresponding author: Mohamed Osman Mohamed Suliman, Head department of Surgery, Nile College, Khartoum, \\ Sudan
}

\begin{tabular}{|c|c|}
\hline ARTICLE INFO & ABSTRACT \\
\hline Received: April 04, 2019 & Citation: Mohamed Osman Mohamed Suliman. Teaching Surgical Skills During the Present \\
\hline Published: 蔧 April 10, 2019 & $\begin{array}{l}\text { Explosion of Knowledge and Technologies. Biomed J Sci \& Tech Res 17(1)-2019. BJSTR. } \\
\text { MS.ID.002931. }\end{array}$ \\
\hline
\end{tabular}

\section{Opinion}

The continuous introduction of new technologies into surgery mandated the introduction of new ways of training to cope with it. Mastering the new skills to use the new technologies is mandatory for the success and safety. For example, introduction of laparoscopic surgery needed new types of skills to be taught. Even the different types of laparoscopic operations which were developed by time needed different types of skills. Microscopic, robotic and remote surgeries are, but a few other examples. Teaching these new skills during the postgraduate training program makes it inflated and redundant. To deflate it either the time for postgraduate training increases or some of the skills is taught before entering the training programme. Increasing the time for training is not desired by any. Teaching some skills somewhere else is possible as suggested later.

On the other hand, explosion of knowledge in all surgical fields makes the undergraduate curriculum overloaded. Because of this, the surgical skills which will not be used independently in houseman ship should not be taught in the undergraduate curriculum. Now, in both levels of training we have a problem of time. The aim is to have a well-trained surgeon. The base of this surgeon lies in the undergraduate teaching of surgical skills. The actual making of a surgeon is in the postgraduate training. The solution lies in defining all the surgical skills needed to start the postgraduate training and then find the most suitable place for them. Most of the surgeons who train the postgraduates also teach the undergraduates. These surgeons should be actively involved in revision of both under and postgraduate curricula. These surgeons also supervise house officers and know the skills they need to start houseman ship. They know all the surgical skills that are needed to start the postgraduate programme. The surgical skills which are needed to start the houseman ship should be taught for the undergraduates. Those which are not needed to start the houseman ship should be taught during the houseman ship.

My opinion is that there is no need for medical students to attend surgical operations. The skills gained from attending operations can be taught in the skill lab. Their presence in the operating room will crowed it, putting them in the way of the real staff. They increase the hazard of infection and mostly they do not participate really in operations, so, they learn nothing. This can decrease the load on the students and give them more time to master the important surgical skills. In my opinion, the distribution of skills should be as follows:

The surgical skills which are needed to start the houseman ship and should be included in the undergraduate curriculum are: (They are NOT written in order of preference)
a. CPR.
b. Surgical Audit.
c. Surgical ethics.
d. Professionalism.
e. Communication skills.
f. Scrupping.
g. Glove wearing.
h. Simple suturing.
i. Basic knot tying.
j. Urethral catheterization.
k. Naso-gastric intubation. 
l. Intravenous injection and cannulation.

m. Pharyngeal airway placement.

n. Cervical collar application.

o. Suture removal.

p. Bag mask \& nasal prongs ventilation.

q. All clinical skills needed for examination of a surgical patient including digital examination of the anus/rectum and vagina.

The surgical skills to be taught during the houseman ship: (They are NOT written in order of preference)
a) ATLS.
b) Deep knot tie.
c) Chest intubation.
d) Tracheostomy \& Cricothyroidotomy.
e) Mattress suture.
f) Subcuticular suture.
g) Surgical incisions.
h) Positioning of patients on the surgical table for different operations.

\section{ISSN: 2574-1241}

DOI: 10.26717/BJSTR.2019.17.002931

M Osman Mohamed Suliman. Biomed J Sci \& Tech Res

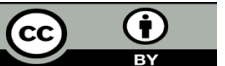

This work is licensed under Creative

Commons Attribution 4.0 License

Submission Link: https://biomedres.us/submit-manuscript.php i) Simple skin excisions.

j) Anoscopy/proctoscopy.

k) Abdominal paracentesis.

l) Plaster cast/splint limb immobilization.

m) Handling and use of different surgical instruments.

n) Application and removal of skin staples.

o) Removal of drains.

p) Arterial blood sampling.

q) Application of local anesthesia.

r) Skills for laparoscopy and other new technologies.

The last skills should be gained by simulation courses which are designed by the postgraduate trainers and conducted by recognized bodies such as the Continuous Professional Development. They can be considered a prerequisite for admission into the postgraduate surgical training programme. It is really annoying when you, a postgraduate trainer, discover that many of your trainees do not know many of the basic surgical skills. Evaluation for these skills should be included in the assessment for completion of medical school and houseman ship.

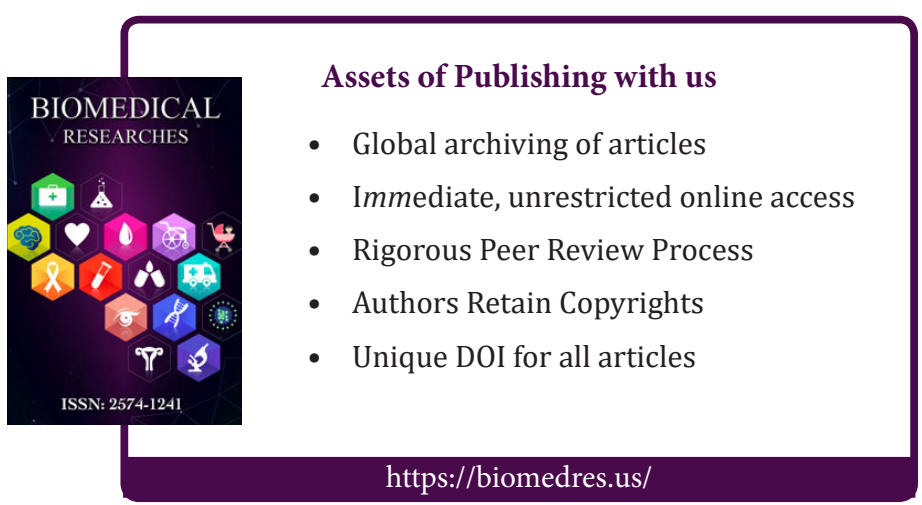

